\title{
Breaking Down "Firewall"' Among Public Relations And Journalism
}

\author{
Jamroji, Nasrullah \\ Universitas Muhammadiyah Malang \\ Email: jamroji@umm.ac.id, nasrullah@umm.ac.id
}

\begin{abstract}
Public Relations $(P R)$ and journalism are often disputed in theory and practice. While PR is an activity that aims to improve goodwill, trust, mutual understanding and a good image of the community or society, in the other hand journalism has a social responsibility to provide accurate information for the community through the media. The increase of communication technology has been changing business media and also affected the PR strategy in Indonesia that bring together PR and journalism as one of campaign strategies. The boundary between $P R$ and journalism does not exist anymore. The firewall concept that separates roles of journalism, advertising, and PR now is blurred. Paid microsites, advertorials, and Media Relations practices such as press tours, press releases, press gatherings, led to the emergence of journalistic work with a 'smooth' PR approaches to increase the image of the person and institution. It can't call journalism, because it leads interests that the public does not necessarily want, despite using journalism rules in coverage.
\end{abstract}

Keywords: Journalism, Public Relations, Firewall

\section{Pendahuluan}

Banyak orang berpendapat, profesi

Public Relations (PR) merupakan pekerjaan yang banyak berhubungan dengan orang lain dalam pengertian yang lebih luas. Tidak salah, tapi profesi PR sesungguhnya lebih banyak mengarah pada pemecahan masalah (problem solving) dan bekerja dengan media. PR adalah fungsi manajemen yang khas yang membantu membangun dan mempertahankan jalur komunikasi, pemahaman, penerimaan, dan kerja sama antara organisasi dan publiknya; melibatkan manajemen masalah atau masalah; membantu manajemen untuk mendapatkan informasi dan responsif terhadap opini publik; mendefinisikan dan menekankan tanggung jawab manajemen untuk melayani kepentingan publik; membantu manajemen tetap mengikuti dan memanfaatkan perubahan secara efektif, berfungsi sebagai sistem peringatan dini untuk membantu mengantisipasi tren; dan menggunakan penelitian dan teknik komunikasi etis sebagai alat utamanya (Harlow, dalam Wilcox et al. 2003 dalam Theaker, 2004: 4).

Salah satu deskripsi tugas PR adalah Media Relations. Menjalin hubungan baik dengan media menjadi hal 
yang wajib dilakukan oleh PR. Mengingat media merupakan sarana publikasi tentang segala informasi yang berhubungan dengan sebuah institusi. Selain itu media juga berfungsi untuk membangun reputasi. Dalam beberapa tahun terakhir internet telah menjadi tempat berkumpul dengan cara yang lebih mudah. Semua orang bisa berbicara tentang apapun, dari manapun, dengan kepentingan apapun dalam satu forum secara virtual.

Internet dengan fungsi barunya, telah merubah wajah PR konvensional menjadi PR digital. Contoh paling nyata adalah penggunaan website dan media sosial untuk sosialisasi dan promosi sesuai dengan goal attainment lembaga. Media sosial atau media lain dari medium internet dapat dipergunakan dengan leluasa untuk kepentingan kinerja PR saat ini.

Tidak hanya PR, bentuk media massa juga berubah. Di era konvensional, media memiliki batasan yang jelas mempublikasikan konten berbentuk berita atau advertorial. Ketika internet masuk, industri media massa banyak yang menyesuaikan diri dengan platform baru ini. Mereka berbenah menentukan bentuk baru dengan konvergensi dengan internet. Tidak sekedar bentuk, mereka juga merubah strategi bisnis media online menjadi lebih menguntungkan. Menampilkan lebih banyak berita dengan hitungan detik, karena konsumsi informasi yang kian cepat dari pembaca. Perubahan bentuk ini, membuat industri media mengalami penurunan drastis dalam oplah penjualan kaoran atau majalah. Berbagai macam strategi dilakukan media untuk sustain. Salah satunya melakukan praktik penulisan berita berbayar.

Dalam buku The Elements of Journalism (Kovach \& Rosentiel, 2001) menyatakan, ada sembilan elemen jurnalisme - sekarang disempurnakan menjadi sepuluh yang harus dimiliki wartawan. Diantaranya Jurnalis harus tetap independen dari pihak yang mereka liput. Firewall yang dulu merupakan batasan jelas antara jurnalistik dan advertorial, kini blured. Dalam praktek kerja PR hubungannya dengan media massa, hal ini bukan menjadi hal baru lagi. Media membutuhkan support ekonomi untuk bertahan hidup, dan PR memanfaatkan celah ini untuk melakukan branding dan support kerja mereka. Penelitian ini dilakukan untuk melihat runtuhnya konsep dinding api dalam media massa. Selain itu juga melihat berbagai praktik yang dilakukan PR Lembaga Pemerintah dan Lembaga Sosial, yang menyumbangkan signifikansi bahwa tidak ada lagi batasan firewall di media massa.

Konsep branding pada PR, konsep "menjual" pada advertising, dalam 
realitanya kini tidak lagi memiliki dinding pembatas yang jelas dengan Jurnalistik. Dinding pembatas antara semuanya kini sudah kabur. Hal ini sejalan dengan perkembangan teknologi komunikasi yang pesat dalam satu dekade terakhir. Firewall merupakan dinding pembatas yang jelas antara publikasi Jurnalistik dan Advertorial di media massa.

Dalam dunia PR maupun Jurnalistik, perkembangan digital merupakan fase transisi. Kedua bidang tersebut menjajaki medium baru ini melalui dua perspektif besar yang berbeda. Media memakai pendekatan digital sebagai sikap bertahan menghadapi perubahan teknologi dan memenuhi kebutuhan masyarakat akan akses informasi. Dunia Jurnalistik kini harus berkompetisi lebih luas, karena tuntutan kebutuhan informasi. Sosial media sebagai platform baru menjadi kesempatan yang memungkinkan produk jurnalistik dapat disebar luaskan dengan mudah ke pembaca, meningkatkan tingkat keterlibatan, dengan jangkauan yang lebih luas, (Lloyd and Toogood, 2015).

Sementara PR memandang digital sebagai peluang untuk bereksplorasi. Mereka memiliki pola baru tentang "pasar" dan cara baru mengelola dan menempatkan konten branding institusi mereka. Kondisi ini menciptakan platform yang benar-benar baru dalam dunia PR, karena mereka bisa dengan sangat bebas menentukan konten dalam media digital tanpa melalui editorial checking seperti yang terjadi pada media analog sebelumnya.

Tujuan dari firewall ini, menurut Cotter adalah untuk membangun objektivitas laporan berita, untuk mempertahankan etika jurnalistik. Firewall ini juga adalah batasan psikologis yang ada bahkan dalam setting fisik di mana newsroom dan bagian iklan bekerja secara terbuka di tempat yang sama. Staf produksi berita (reporter, desain, foto dan lainnya), bertanggung jawab untuk memproduksi berita harus menyadari keberadaan tembok pemisah ini. Untuk menjaga firewall ini ada beberapa aturan yang kerap ditegakkan, seperti tidak ada opini personal dalam tulisan dan iklan secara jelas dipisahkan dari konten editorial dan diungkapkan secara nyata sebagai iklan. Keputusan yang diambil dalam redaksi tidak seharusnya termotivasi oleh ekonomi (Cotter dalam Pasandaran \& Octavianto, 2017).

Dengan berbayar, kini hampir semua iklan dapat ditulis dan ditempatkan di koran yang disamarkan sebagai berita. Tanpa penjelasan apapun yang memungkinkan pembaca membedakan antara materi yang telah dibayar oleh pengiklan, dan apa yang dihasilkan oleh 
reporter koran sendiri, (https://ethics.journalism.wisc.edu/2012/12 /19/breaking-down-the-wall/).

Public Relations (PR) sebagai salah satu perspektif dalam llmu Komunikasi telah berkembang menjadi sebuah profesi yang penting. Profesi PR saat ini telah sejajar dengan berbagai profesi lain seperti marketing, penjualan, akuntan, human resource, psikolog, jurnalis dan sebagainya. Menurut Cutlip and Center's Efective Public Relations (Broom \& Sha, 2013), fungsi PR sangat penting dalam sebuah organisasi, yaitu fungsi manajemen yang menilai sikap publik, mengidentifikasi kebijaksanaan dan tata cara seseorang atau organisasi demi kepentingan publik, serta merencanakan dan melakukan suatu program kegiatan untuk meraih pengertian dan dukungan publik.

Pendapat ini diperkuat oleh Rex Harlow (dalam Ruslan, 2010:16) yang menyatakan bahwa PR adalah fungsi manajemen yang khas untuk mendukung pembinaan, pemeliharaan jalur bersama antara organisasi dengan publiknya, menyangkut aktivitas komunikasi, pengertian, penerimaan dan kerja sama; melibatkan manajemen dalam menghadapi persoalan/permasalahan, membantu manajemen dalam mengikuti dan memanfaatkan perubahan secara efektif; bertindak sebagai sistem peringatan dini dalam mengantisipasi kecenderungan penggunaan penelitian serta teknik komunikasi yang sehat dan etis sebagai sarana utama.

Kata kunci dalam fungsi PR tersebut di atas adalah fungsi manajemen untuk berkomunikasi ke publik. Ada dua publik yang menjadi sasaran, yaitu publik internal dan ekternal. Publik internal adalah orang-orang yang berada atau tercakup dalam organisasi, dari manajemen puncak hingga seluruh karyawan. Publik eksternal adalah orang-orang di luar organisasi yang terkait erat dalam rantai nilai (value chain) organisasi, seperti supplier, konsumen, pemerintah, investor, masyarakat/komunitas, dan media massa.

Pada dasarnya PR adalah kegiatan yang bertujuan untuk memperoleh goodwill, kepercayaan, saling adanya pengertian dan citra yang baik dari publik atau masyarakat pada umumnya. Perkembangan PR seperti tidak pernah ada habisnya. Setelah hadirnya internet, perkembangan PR banyak berkembang dalam ruang-ruang virtual dan sangat mempengaruhi perubahan strategi di bidang ini.

Pada awalnya, banyak PR mengoptimalkan penggunaan blog, untuk membentuk opini tentang lembaga mereka, (Stypulkowski, 2009:10). Komentar positif 
tentang perusahaan di forum diskusi online akan mempengaruhi persepsi orang terhadap perusahaan dalam arah yang positif (Park \& Lee, 2007). Juga dicatat bahwa praktisi pemasaran dan PR harus aktif dalam forum yang membawa relevansi bagi perusahaan mereka untuk berpartisipasi dalam dialog dengan para pengguna (Park \& Lee, 2007).

Pandangan jurnalisme sebagai profesi mengidentifikasi integritas. Diukur dengan komitmen terhadap kebenaran, tidak mengedepankan keuntungan pribadi, sebagai karakteristik utama dari seorang jurnalis profesional. Integritas didefinisikan sebagai kepatuhan pada kewajiban sosial yang melekat pada posisi istimewa - kekuatan media untuk menyebarluaskan informasi harus diimbangi dengan kewajiban sosial terhadap kebenaran dan keadilan. Integritas dalam konteks ini dipahami sebagai konsistensi yang memastikan jurnalis akan mendahulukan kepentingan publik di atas keuntungan mereka sendiri dalam menyampaikan kebenaran, (Burns, 2002:16).

Pergeseran makna jurnalisme selama 10 tahun terakhir ke 'jurnalisme yang memenuhi permintaan pasar' telah secara mendasar mengubah peran para jurnalis dalam membuat berita. Perubahan tersebut ditandai oleh kurangnya independensi editorial dalam organisasi media. Gaunt (1990: 146) dalam buku Choosing the News: The Profit Factor in News Selection menyatakan bahwa manajer media yang berorientasi pada keuntungan bukan hal baru. Namun yang membuat terlihat baru, adalah inovasi teknis yang diperkenalkan oleh manajemen media yang berorientasi pada laba. Marketdriven journalism menempatkan penekanan pada konten. Selain itu prediktabilitas lebih disukai daripada fleksibilitas, untuk dapat memastikan banyaknya pengiklan yang masuk.

McManus (1994: 203) berpendapat bahwa komodifikasi berita sebagai produk untuk dijual kepada pengiklan menciptakan konflik kepentingan dalam media itu sendiri. Para pemangku kepentingan dalam upaya mencari keuntungan perusahaan, menggunakan cara menjual 'berita' sebagai produk kepada orang-orang yang memiliki kepentingan terhadap publikasi media.

Saat ini kondisi jurnalisme beritegritas sedang berada di garis bawah. Internet memiliki andil besar dalam penurunan penjualan surat kabar, menyusutnya ruang redaksi, blog menjamur, dan pembaca beralih ke konten gratis. Burns (2013) dalam buku Understanding Journalism edisi kedua berpendapat, jurnalisme lebih dari sekadar 
penguasaan teknis murni. Adaptasi terhadap kemajuan digital menjadi keniscayaan yang harus dihadapi industri media untuk berbenah menuju konvergensi.

Bentuk media massa berubah setelah difusi internet; jurnalisme radio, televisi dan cetak tidak sama lagi seperti sebelumnya. Pertumbuhan difusi internet ini merubah pola industri media massa. Jika sebelumnya redaksi memiliki independensi yang tinggi terhadap berita yang akan dimuat atau ditayangkan, kini dengan adanya internet informasi harus tersaji dalam hitungan detik.

Internet telah membuat akses informasi manusia semakin mudah, sebab semua dapat diakses melalui software yang sama dalam jaringan virtual. Saat ini sedikit sulit membedakan situs berkualitas tinggi dan bonafid dengan situs yang lain. Kredibilitas website sebagai sumber informasi, merupakan perhatian utama. Hingga tahun 2017 pengguna internet di Indonesia mencapai 143,26 juta jiwa atau setara dengan $54,7 \%$ dari total populasi penduduk. Angka ini meningkat dibandingkan tahun 2016, yang menyentuh angka 132,7 juta jiwa, (APJII, 2018: 3). Artinya, tingginya pengakses informasi menunjukan adanya ketertarikan akan informasi yang mudah untuk diperoleh melalui internet. Website, aplikasi mobile phone, portal media, dan berbagai sumber informasi disediakan internet dengan mudah dan mudah dijangkau kapanpu dan dimanapun.

Ekonomi politik komunikasi adalah istilah yang digunakan secara umum untuk memadukan kerangka teoritik komunikasi dengan kerangka teoritik politik dan ekonomi. Keterikatan pada kajian ekonomi dan politik menjadikan komunikasi menjadi ranah yang rentan terhadap pengaruh keduanya. Sebagai entitas yang dikonstruksi oleh media, apa yang disebut sebagai komunikasi sering merepresentasikan kepentingan ekonomi sekaligus politik tertentu. Vincent Mosco dalam bukunya "The Political Economy of Communication" menyebutkan bahwa definisi ekonomi politik adalah: "the study of relations, particularly the power relations, that mutually constitute the production,distribution, and consumption of resources", (Mosco, 1996:25).

Vincent Mosco menawarkan tiga konsep penting untuk mendekatinya, yaitu: komodifikasi, komersialisasi, spasialisasi dan strukturasi, (Mosco, 1996:139). Ekonomi politik merupakan salah satu cara atau perspektif untuk melihat dan menganalisis suatu isu atau fenomena komunikasi. Dalam menganalisis isu atau fenomena tersebut, terdapat 4 karakter penting dari perspektif ekonomi politik 
yaitu, ekonomi politik berdasar dari kajian perubahan sosial dan trasformasi historis, menjelaskan tentang totalitas dari relasi sosial yang membentuk ranah ekonomisosial-budaya, berkomitmen pada filsafat moral dan memiliki ketertarikan atas nilai sosial serta prinsip moral, dan yang terakhir adalah sosial praksis yang artinya fenomena tersebut memang terjadi dalam realitas.

\section{Metodologi}

Studi yang dilakukan dalam penelitian ini menggunakan pendekatan kualitatif dengan tipe penelitian eksploratif. Pendekatan kualitatif dipilih karena dalam kajian ini tidak bermaksud untuk menguji teori, akan tetapi lebih berorientasi untuk eksplorasi guna memahami fenomena atau gejala bergersernya praktik Public Relations dan Jurnalistik di era konvergensi media.

\section{Penelitian tipe eksploratif} dimaksudkan untuk penjajakan suatu topik baru, mejelaskan gejala atau kondisi tertentu atau mencari jawaban kenapa sebuah fenomena terjadi. Maka tujuan penelitian ekploratif adalah untuk melakukan generalisasi atas suatu proses, aktifitas, situasi yang sedang dipelajari melalui proses induktif (Given; 2008:327).

Data dikumpulkan dengan wawancara kepada kepala Biro
Komunikasi dan Layanan Masyarakat (BKLM) dan Ketua LAZIZMU. Selain wawancara, untuk mendapatkan data bagaimana parktek praktek Public Relations dan jurnalistik saling berhimpitan kepentingan maka peneliti endokumentasikan berita-berita di media massa baik cetak maupun online yang terkait dengan dua lembaga yang menjadi obyek penelitian, yaitu Kementrian Pendidikan Nasional mewakili lembaga pemerintah dan LAZISMU mewakili lembaga Sosial.

\section{Hasil dan Pembahasan}

Memahami runtuhnya Firewall antara Public Relations (PR) dan Jurnalistik dalam penelitian ini yaitu dengan memaparkan beberapa kasus. Pertama melihat kinerja PR Pemerintah dalam publikasi di media massa. Disusul paparan tentang strategi PR Lembaga Sosial yang juga memiliki strategi "soft" publikasi.

\section{PR Lembaga Pemerintah Optimalkan} Value Chain dan Berita Berbayar

Kementrian Pendidikan dan Kebudayaan (Kemendikbud) memiliki istilah lain untuk PR yaitu Biro Komunikasi dan Layanan Masyarakat (BKLM). Biro ini berperan melaksanakan koordinasi dan pengelolaan informasi, 
publikasi hubungan antarlembaga, dan layanan masyarakat di bidang pendidikan dan kebudayaan. Pada konsep pemasaran digital strategis, keberhasilan sebuah perusahaan atau institusi ditunjukkan jika iklan menjangkau sebanyak mungkin audiens. Dengan menggunakan jenis digital, meningkatkan jumlah orang yang mengakses iklan dan mempermudah mereka menemukan informasi tentang institusi atau sebuah merek, (Preston, 2018).

Publikasi yang dilakukan BKLM, mengacu pada audiensnya yang terbagi atas siswa usia sekolah mulai dari Taman Kanak-kanak (TK), SD, SMP, SMA, Guru, dan Orangtua. Dalam melakukan publikasi, BKLM telah memiliki peta media yang sesuai dengan segmen yang dituju. Segmen yang dimaksud disini adalah Publik eksternal atau orang-orang di luar organisasi yang terkait erat dalam rantai nilai (value chain) organisasi. $70 \%$ Value Chain Kemendikbud adalah remaja milenial mulai dari SD hingga SMA. Sisanya adalah Guru dan Orangtua. Maka medium yang banyak dipakai untuk mensosialisasikan program atau informasi adalah media online. Baik media sosial maupun website atau media massa online. Dr. Ir. Ari Santoso, DEA, Kepala BKLM Kemendikbud mengungkapkan bahwa media online lebih dapat dipertanggungjawabkan:

"media online itu yang lebih banyak dilihat. Bisa dipertanggungjawabkan keefektivitasannya, dibandingkan dengan media cetak sama TV... Online itu jauh lebih efisien, murah, dan sasarannya sudah jelas." (Wawancara tanggal 6 Agustus 2018).

BKLM memiliki peta, yang meyatakan bahwa 1 dari 3 penduduk Indonesia adalah Milenial. 8 dari 10 generasi Milenial terkoneksi dengan internet. 40,1\% generasi Milenial memiliki akun media sosial Instagram, sementara $22,3 \%$ lainnya masih membaca surat kabar, (Ali, 2018). Dasar ini yang dipakai BKLM untuk menentukan medium untuk publikasi.

Selain itu Kepala BKLM juga mengatakan jika pihaknya banyak memangkas anggaran advertorial. Namun berita berbayar dipilih sebagai solusi untuk publikasi ke media online. Berita berbayar ini yang disebut sebagai advertorial berbentuk berita.

"kita sekarang masuknya advertorial yang masuk ke body news. Betul-betul ke body news. Jadi advertorial, tapi packagingnya berita. Jadi nggak kentara begitu. Sekarang kita lakukan itu. News itu nilai jualnya lebih tinggi dibandingkan advertorial karena saya sendiri pun nggak pernah baca advertorial".(Wawancara tanggal 6 Agustus 2018). 
Komunikasi dalam media massa, sering merepresentasikan kepentingan ekonomi sekaligus politik tertentu. Vincent Mosco dalam bukunya "The Political Economy of Communication" menyebutkan bahwa ekonomi politik adalah: "the study of relations, particularly the power relations, that mutually constitute the production, distribution, and consumption of resources", (Mosco, 1996:25). Pergeseran makna jurnalisme selama 10 tahun terakhir ke jurnalisme yang memenuhi permintaan pasar' telah secara mendasar mengubah peran para jurnalis dalam membuat berita. Perubahan tersebut ditandai oleh kurangnya independensi editorial dalam organisasi media.

Konten berita sudah layaknya komoditas, atau barang dagangan untuk memperoleh keuntungan ekonomi untuk sustainability media. Sementara politik bermain di ranah ideologi media, sebagai pembentuk opini publik. Dalam buku The Elements of Journalism (Kovach \& Rosentiel, 2001) menyatakan, ada sembilan elemen jurnalisme. Diantaranya Jurnalis harus tetap independen dari pihak yang mereka liput. Dalam wawancara dengan Kepala BKLM yang menyebutkan bahwa lebih menyukai advertorial, tapi packagingnya berita, dalam bahasa Bill Kovach dan Tom Rosential kondisi ini tidak memenuhi hak publik akan informasi yang proporsional dan independen. Selain itu juga menyalahi kode etik jurnalistik.

Dalam Kode Etik Jurnalistik Wartawan Indonesia Pasal 6 disebutkan bahwa, "wartawan Indonesia tidak menyalahgunakan profesi dan menerima suap“. Segala pemberian dalam bentuk uang, benda, atau fasilitas dari pihak lain yang mempengaruhi independensi disebut suap. Dalam kasus ini, meminjam bahasa Mosco bukan lagi suap namun sesuatu yang dikondisikan untuk kepentingan ekonomi media, berita sudah menjadi komodifikasi dan tidak lagi memiliki independensi, advertorial dalam bentuk berita tersebut sudah membentuk strukturasi dalam industri media. Dengan demikian, Firewall yang dulu merupakan batasan jelas antara jurnalistik dan advertorial, kini blured. Dalam praktek kerja PR hubungannya dengan media massa, hal ini bukan menjadi hal baru lagi. Media membutuhkan support ekonomi untuk bertahan hidup, dan PR memanfaatkan celah ini untuk melakukan branding dan support kerja mereka. 
Gambar 1;

Contoh berita berbayar yang dilakukan oleh BKLM dan Media Indonesia:

INDONESIA HUN

\section{Kejar Skor PISA} RI Belajar dari Vietnam

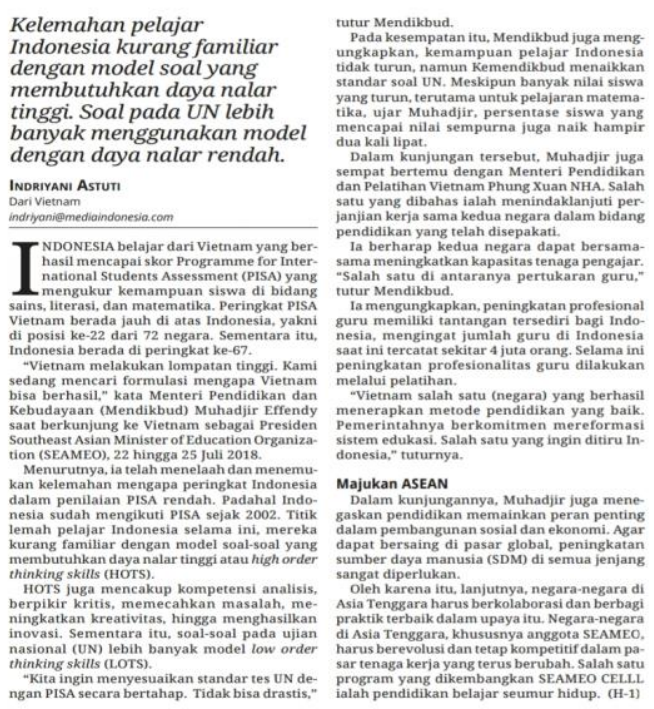

Lembaga Sosial Maksimalkan Owned Media dibanding Paid Media

Sejak disahkan Undang-undang No. 24 tahun 2011 tentang Pengelolaan Zakat, banyak lembaga baru bermunculan. Beberapa organisasi keagamaan memanfaatkan peluang ini untuk membantu mengelola zakat umat, disamping prosentase dana Amil yang dapat dikelola. Salah satu lembaga pengelolaan zakat yang menjadi objek penelitian ini adalah LAZISMU (Lembaga Amil Zakat Infaq dan Shadaqoh Muhammadiyah). Sebagai salah satu organisasi keagamaan terbesar di Indonesia, Muhammadiyah memperkenalkan LAZISMU sebagai lembaga yang terpercaya untuk mengelola Zakat, Infaq, dan Shadaqah. Upaya mendapatkan kepercayaan dan simpati dari masyarakat, dilakukan dengan publikasi melalui berbagai media. Rizaludin Kurniawan, M.Si Direktur Fundraising dan Kerjasama LAZISMU mengatakan:

"LAZISMU sangat memperhatikan betul tentang PR dan media relation ini karena menyangkut citra. LAZISMU sesuai dengan visinya ingin menjadi lebaga yang terpercaya" (Wawancara tanggal 7 Agustus 2018)

dibandingkan dengan Lembaga Pemerintahan, pengelolaan Media Relations di LAZISMU masih sederhana.

Organisasi ini memaksimalkan Owned Media yang mereka miliki, disamping Paid Media yang juga dipergunakan sebagai alat publikasi. Owned Media yang mereka miliki diantaranya inhouse magazine Matahati, website LAZISMU www.lazismu.org, Instagram, Facebook, dan Twitter. Rizaludin menjelaskan Paid media yang dimanfaatkan oleh LAZISMU:

"Kita ada kerjasama dengan TVMU dalam jangka panjang, juga ada kerjasama dengan Google adds, Facebook adds. Kita juga ada kontrak untuk menopang itu dengan 
beberapa agensi, seperti digital marketing, dan itu berbayar dengan mereka“ (Wawancara tanggal 7 Agustus 2018).

Dalam praktek Media Relations LAZISMU ini, kesan Firewall antara advertorial dan Jurnalism masih terkesan jelas. Diperjelas dengan statement Rizaludin yang menyatakan jika tidak ada kontrak Advertorial, mereka akan mengundang wartawan dan mengirimkan Press Release ke semua media massa. "Ada yang berbayar, seperti advertorial, ada juga yang tidak berbayar seperti kita undang mereka dalam beberapa event" (Wawancara tanggal 7 Agustus 2018).

Statement tersebut berbanding terbalik dengan adanya beberapa berita tentang LAZISMU di media massa yang terindikasi berbayar. Seperti contoh berita di bawah ini, Kompas.com memberitakan tentang LAZISMU yang membuka bantuan untuk Rohingya disertai nomor rekening. Dalam dunia marketing, ini disebut soft-selling atau menjual dengan cara halus. Kemasannya berita, namun isinya untuk menarik orang supaya tertarik dan membeli sebuah produk.
Gambar 2;

Contoh berita owned media:

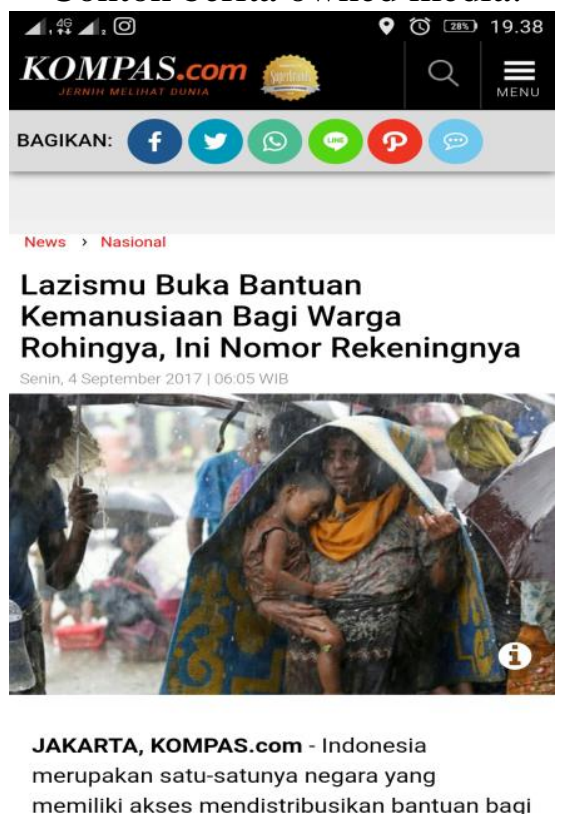

Komentar positif tentang perusahaan di forum online akan mempengaruhi persepsi orang terhadap perusahaan dalam arah yang positif (Park \& Lee, 2007).

\section{Penutup}

1. PR Lembaga pemerintah menggunakan strategi Media Relations yang lebih kompleks dan profesional dibanding Lembaga Sosial.

2. Lembaga Pemerintah menggunakan mapping Value Chain yaitu Milenial, sehingga publikasi yang dilakukan lebih efektif dan tepat sasaran.

3. Pelanggaran Etika Jurnalistik terjadi dalam Paid Media yang dilakukan oleh Lembaga Pemerintah dan Lembaga Sosial berupa advertorial berbentuk berita. 


\section{Daftar Pustaka}

Ali, Hasanuddin. 2018. 9 Perilaku Milenial Indonesia. Jakarta: Alvara Research Center

APJII. 2018. Survei APJII: Penetrasi Internet di Indonesia Capai 143 Juta Jiwa. Buletin APJII Edisi Maret.

https://apjii.or.id/downfile/file/BUL ETINAPJIIEDISI22Maret2018.pdf

Broom, Glen M. \& Sha, Bey-Ling. 2013. Cutlip and Center's Efective Public Relations Eleventh Edition. Essex: Pearson

Burns, Lynette Sheridan. 2002. Understanding Journalism. London: Sage Publications

2013.

Understanding Journalism Second Edition. London: Sage Publications

Gaunt, P. 1990. Choosing the News: The Profit Factor in News Selection.

New York: Greenwood Press

Given, Lisa M. 2008. The Sage Encyclopedia of Qualitative Research Methods, Los Angeles, Sage.

Kovach, Bill \& Rosentiel, Tom. 2001. The Elements of Journalism: What Newspeople Should Know and the Public Should Expect. New York: Crown Publisher

Lloyd, John and Toogood, Laura. 2015. Journalism and PR News Media and Public Relations in The Digital Age. London: I.B Tauris Co. Ltd. \& Reuters Institute for the Study of Journalism

McManus, J. 1994. Market-Driven Journalism: Let the Citizen Beware. Thousand Oaks, CA: Sage
Mosco, Vincent. 1996. The Political Economy of Communication: Rethinking and Renewal. London: Sage Publication

Park, Namkee \& Lee, Kwan Min. 2007. Effects of Online News Forum on Corporate Reputation. Public Relations Review. Vol 33 Issue 3. https://www.sciencedirect.com/scie nce/article/abs/pii/S0363811107000 744

Pasandaran, Camelia C \& Octavianto, Adi W. 2017. Editorial Firewall pada Media Online dengan Native Advertising (Studi Kasus Microsite Merdeka.com dan Republika). id.m.spsindonesia.org/file/_/3v4fec 0c4kwt9

Preston, Mary Jo. 2018. The Digital Media Trifecta: 3 Essential Strategies for Your Brand. https://www.streamcreative.com/bl og/the-digital-media-trifecta-3essential-strategies-for-your-brand

Ruslan, Rosady. 2010. Manajemen Public Relations\&Media Komunikasi. Jakarta: PT Raja Grafindo Persada.

Stypulkowsky, David. 2009. PR 2.0 - The New PR. Master Thesis. Swedish: Órebro University. http://www.precis.se/wpcontent/uploads/2012/06/uppsat10. pdf

Theaker, Alison. 2004. The Public Relations Handbook. Oxfordshire: Routledge 

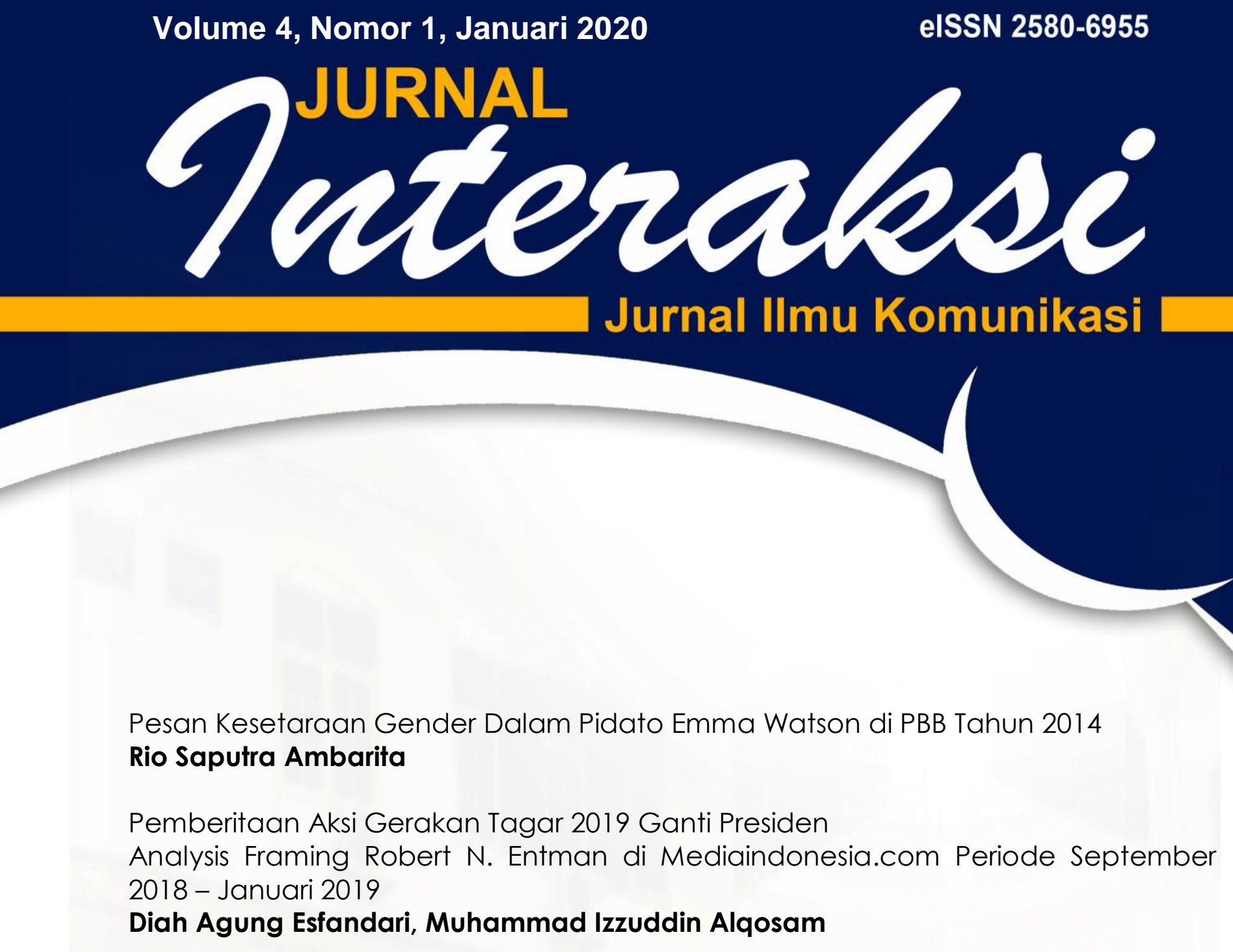

Branding Dan Positioning Identitas Budaya Indonesia Dalam Pesan Iklan TV Komersial Bejo Bintang Toedjoe Jahe Merah

Agus Hermanto, Sa'diah El Adawiyah

Identifikasi Faktor-Faktor Yang Mempengaruhi Minat Berkunjung Ke Olivier Café, Jakarta

\section{Tashia Tariq}

Studi Analisis Isi Pesan Dakwah Dalam Media Sosial Instagram @dakwah_tauhid Agus Triyono, Nifsya Khaira Marhuda

Relasi Politik, Bullying dan Etika Mengenai Isu "Muslim Uighur" di Media sosial Yofiendi Indah Indainanto

Breaking Down "Firewall" among Public Relations and Journalism Jamroji, Nasrullah

Strategi Komunikasi untuk Program Corporate Social Responsibility dalam Pemberdayaan Masyarakat

Arifin Saleh, Mislan Sihite 


\section{Turetralesi Jurnal IImu Komunikasi}

Jurnal Interaksi diterbitkan oleh Universitas Muhammadiyah Sumatera Utara (UMSU) bekerjasama dengan Asosiasi Pendidikan Ilmu Komunikasi Perguruan Tinggi Muhammadiyah (APIK PTM) yang terbit dua kali d alam setahun pada bulan Januari dan Juli. Terbit pertama kali pada bulan Januari 2017.

Jurnal Interaksi memuat tulisan yang difokuskan pada pemikiran kontemporer Ilmu Komunikasi, Media, Teknologi Komunikasi, Komunikasi Terapan, dalam berbagai sudut pandang atau perspektif. 


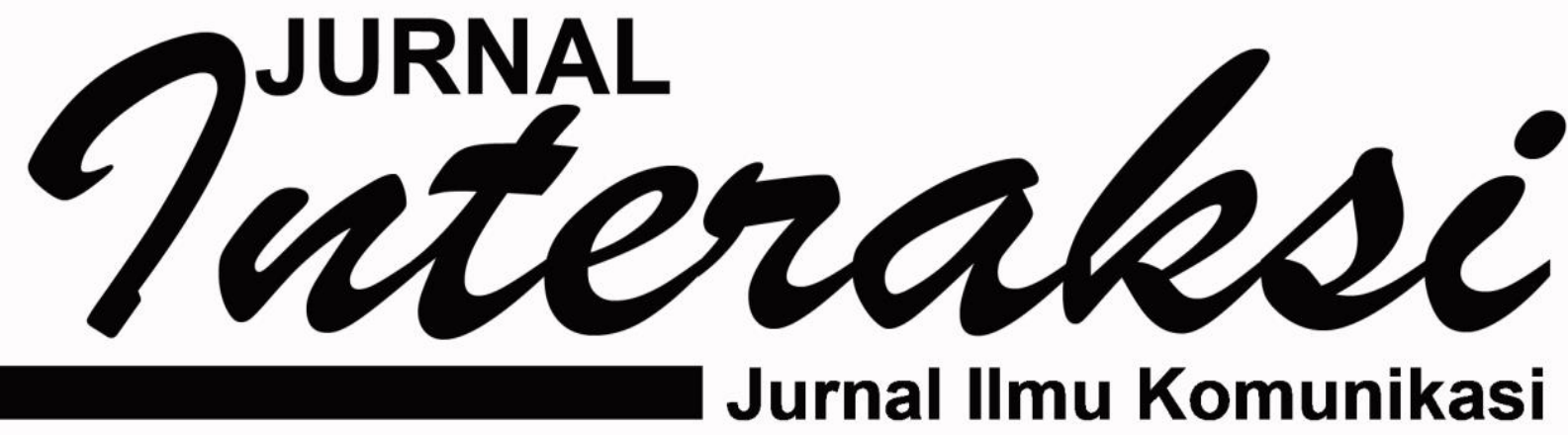

Pesan Kesetaraan Gender Dalam Pidato Emma Watson di PBB Tahun 2014 Rio Saputra Ambarita

Pemberitaan Aksi Gerakan Tagar 2019 Ganti Presiden

Analysis Framing Robert N. Entman di Mediaindonesia.com Periode September 2018 - Januari 2019

Diah Agung Esfandari, Muhammad Izzuddin Alqosam

Branding Dan Positioning Identitas Budaya Indonesia Dalam Pesan Iklan TV Komersial Bejo Bintang Toedjoe Jahe Merah

Agus Hermanto, Sa'diah El Adawiyah

Identifikasi Faktor-Faktor Yang Mempengaruhi Minat Berkunjung Ke Olivier Café, Jakarta

Tashia Tariq

Studi Analisis Isi Pesan Dakwah Dalam Media Sosial Instagram @dakwah_tauhid Agus Triyono, Nifsya Khaira Marhuda

Relasi Politik, Bullying dan Etika Mengenai Isu "Muslim Uighur" di Media sosial Yofiendi Indah Indainanto

Breaking Down "Firewall" among Public Relations and Journalism Jamroji, Nasrullah

Strategi Komunikasi untuk Program Corporate Social Responsibility dalam Pemberdayaan Masyarakat

Arifin Saleh, Mislan Sihite 


\section{Tuteralese}

Volume 4 Nomor 1 Edisi Januari 2020

\section{DAFTAR ISI}

\section{$1-11$}

Pesan Kesetaraan Gender Dalam Pidato Emma Watson di PBB Tahun 2014 Rio Saputra Ambarita

\section{$12-23$}

Pemberitaan Aksi Gerakan Tagar 2019 Ganti Presiden

Analysis Framing Robert N. Entman di Mediaindonesia.com Periode September 2018 - Januari 2019

\section{Diah Agung Esfandari, Muhammad Izzuddin Alqosam}

\section{4-40}

Branding Dan Positioning Identitas Budaya Indonesia Dalam Pesan Iklan TV Komersial Bejo Bintang Toedjoe Jahe Merah

Agus Hermanto, Sa'diah El Adawiyah

\section{1-49}

Identifikasi Faktor-Faktor Yang Mempengaruhi Minat Berkunjung Ke Olivier Café, Jakarta

\section{Tashia Taria}

\section{0-67}

Studi Analisis Isi Pesan Dakwah Dalam Media Sosial Instagram @dakwah_tauhid Agus Triyono, Nifsya Khaira Marhuda

\section{8-85}

Relasi Politik, Bullying dan Etika Mengenai Isu "Muslim Uighur" di Media sosial Yofiendi Indah Indainanto

\section{6-97}

Breaking Down "Firewall" among Public Relations and Journalism Jamroji, Nasrullah

98-105

Strategi Komunikasi untuk Program Corporate Social Responsibility dalam Pemberdayaan Masyarakat

Arifin Saleh, Mislan Sihite 